\title{
Europe's arrested development
}

\section{Encouraging statistics on industrial R\&D don't tell the whole story.}

V ajor companies in Europe are at last spending more on research and development (R\&D), according to figures released earlier this month. The news is a welcome, albeit belated, indication that they are responding to the challenges posed by their global competitors.

The largest 1,000 companies in the European Union (EU) increased their total R\&D spending by $5.3 \%$ last year, the preliminary data released by the European Commission reveal. This spending will not, in itself, result in the level of innovation that European industry requires to remain competitive. It does, however, indicate that one element of the overall picture - large-scale industrial research - is moving in the right direction.

But the Industrial R\&D Investment Scoreboard doesn't tell the whole story. For a start, although it tracks the total R\&D activity of European companies, a large and growing proportion of this takes place outside the EU. The scoreboard also found that the world's top 1,000 companies grew their research even more quickly - by $7.7 \%$ - during 2005. And the officials that compiled the data caution that, despite the growth, European industry still faces structural issues that do not auger well for the future of innovation in the EU.

Political leaders now accept unequivocally that research, development and innovation are critical to Europe's competitiveness, and therefore to the future of the EU. Four years ago, at a summit in Barcelona, they agreed that the EU should attempt to increase its total investment in R\&D to $3 \%$ of its economy.

$R \& D$ as a percentage of economic output is not an ideal metric, and many economists question whether $3 \%$ is an attainable target. Nonetheless, it provides a useful yardstick against which progress can be measured, as it includes total R\&D carried out, not just government expenditure. That's important, as industrial R\&D in Europe is much weaker than in the United States or Japan, and will probably have to strengthen if the continent is to sustain a decent level of economic growth. Not to put too fine a point on it, innovation is the only thing that can prevent European industry being inexorably squeezed between the talent and power of the United States and the rapid industrialization in Asia.

The latest data show, for the first time in the scoreboard's brief three-year history, that research at large European companies has been expanding substantially. Other data, obtained by a European Commission survey of companies' investment plans, indicate that this improvement is likely to be sustained, at least in the medium term. These findings are encouraging.

Both the scorecard and the survey deal with large companies, which between them account for most industrial research. But it is well established that innovation in small companies - or rather, the lack of it - is a critical issue in Europe. Here, too, there are some encouraging signs. There is anecdotal evidence that the old model of European small- and medium-sized firms - as family-owned and intensely conservative - is gradually shifting. According to European Commission officials, a study of employment data suggests that more scientists and engineers are now working for small companies.

But large firms remain a major driver of industrial innovation - and here the outlook is mixed. Sectors of established European strength, such as cars and chemicals, are huge spenders on product development, but they are not particularly research intensive. The sectors that are most research intensive - and that are the main focal points for global innovation - are pharmaceuticals and the broad sphere of activity known these days as information and communications technology (ICT).

The news there is not so good. Many factors contribute to Europe's poor track record in ICT, including the continued fragmentation of the continent's 'common market' and the lack of an innovation engine in any way comparable to California's Silicon Valley. Pharmaceuticals research and the biotechnology industry are both increasingly concentrated in the United States.

The R\&D scoreboard, which will be published in full later in the year, makes a valuable contribution to this discussion by highlighting some of Europe's strengths and weaknesses. Political discourse in Europe currently tends to focus on the expansion of the European Union, and on social issues, such as immigration. Scientists, engineers and business leaders should miss no opportunity to remind their governments of the $3 \%$ target, and to highlight the importance of industrial innovation. Without it, Europe faces a future on the economic sidelines.

\section{Rich in plutonium}

\section{The US nuclear-weapons complex is too large - and is likely to remain so.}

n the wake of North Korea's nuclear-weapons test, little attention has been paid to a revised plan for US nuclear weapons. But details of the scheme emerged on 19 October when officials announced the start of its environmental review. The plan, which focuses heavily on the handling of the plutonium used in nuclear weapons, deserves close scrutiny: it could have wide implications not just for the United States' own nuclear-weapons stockpile, but for the fate of the tattered non-proliferation regime.

The United States currently retains about 50 tonnes of plutonium for military use - enough to fuel some 9,000 warheads. Where it isn't deployed, the plutonium is scattered across the nation's sprawling nuclear-weapons complex.

Last week, officials at the National Nuclear Security Administration (NNSA), the branch of the US Department of Energy that runs the 